\title{
A PCR method for VKORC1 G-1639A and CYP2C9 A $1075 C$ genotyping useful to warfarin therapy among Japanese
}

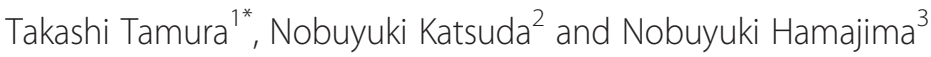

\begin{abstract}
Warfarin is widely prescribed for patients with the risk of thromboembolism around the world. The inter-individual and inter-racial differences in appropriate dosage depend highly on age, body weight, and genetic factors. A lot of studies including genome-wide association studies revealed that vitamin $K$ epoxide reductase complex, subunit 1 (VKORC1) G-1639A and Cytochrome P450 (CYP) 2C9 A1075C are the most strong genetic factors for determining warfarin effects in Asians and Africans. Since we developed a quick and inexpensive genotyping method, polymerase chain reaction with confronting two-pair primers (PCR-CTPP), the method was applied for these genotypes to examine the possibility to clinical use. Subjects were 436 examinees (117 males and 319 females, aged 32 to 85 years) who attended a health checkup program in Japan. The PCR-CTPP for VKORC1 G-1639A and CYP2C9 A1075C was conducted for the subjects, as well as the samples genotyped by DigiTag2 method. The allele frequencies of VKORC1 G-1639A were 0.085 for $G$ and 0.915 for $A$, and those of CYP2C9 A1075C were 0.979 for $A$ and 0.021 for $C$, being in Hardy-Weinberg equilibrium ( $p=0.658$ and $p=0.514$, respectively). These frequencies were similar to those reported in the HapMap project. Genotyping for both SNPs by PCR-CTPP was replicated by DigiTag2 method. Our results indicated that the PCR-CTPP could be one of the alternative methods for genotyping VKORC1 G-1639A and CYP2C9 A1075C for Asians and Africans with similar allele frequencies to Japanese.
\end{abstract}

Keywords: Warfarin; VKORC1 G-1639A; CYP2C9 A1075C; SNPs; PCR-CTPP; Genotyping

\section{Introduction}

Warfarin is one of the most widely prescribed anticoagulants to prevent venous and arterial thromboembolism. This medicine has a very narrow therapeutic range; the high doses increase the risk of bleeding and the low doses do not prevent thromboembolic disorders such as stroke. It is well known that warfarin exhibits large inter-individual and inter-racial differences in the dosage for an appropriate effect. It needs a relatively long time in practice to determine the appropriate dosage for each patient within the optimal prothrombin time measured with an international normalized ratio (PT-INR) range.

Warfarin exerts its anticoagulant effect by inhibiting vitamin K epoxide reductase complex, subunit 1 (VKORC1) (Zimmermann and Matschiner 1974; Suttie 1987). VKORC1

\footnotetext{
* Correspondence: ttamura@gifu-u.ac.jp

${ }^{1}$ Department of Epidemiology and Preventive Medicine, Gifu University

Graduate School of Medicine, 1-1 Yanagido, Gifu 501-1194, Japan

Full list of author information is available at the end of the article
}

recycles vitamin $\mathrm{K}$ 2,3-epoxide to vitamin $\mathrm{K}$ hydroquinone, which is essential for glutamyl carboxylation of clotting factors II, VII, IX, and X (Nelsestuen et al. 1974; Stenflo et al. 1974; Suttie 1987). Several studies have reported that the rare mutations in VKORC1 gene brought clotting factor deficiencies, resulting in warfarin resistance (Li et al. 2004; Rost et al. 2004; D'Andrea et al. 2005). Among them, VKORC1 G-1639A was identified as one of the most strong causes for warfarin dose requirement (Rieder et al. 2005; Yuan et al. 2005).

VKORC1 G-1639A is located at the promoter region of VKORC1 gene (Yuan et al. 2005), and quantitatively changed the expression of VKORC1 protein (Rieder et al. 2005). The promoter with VKORC1 -1639G major allele showed $44 \%$ increase in promoter activity compared with the promoter with $-1639 A$ minor allele (Rieder et al. 2005). These findings have proved that VKORC1 G-1639A is a single nucleotide polymorphism (SNP) to be one of 
the most important factors for explaining individual differences in warfarin dosage.

Cytochrome P450 (CYP) is known to play an integral role in biological oxygenation reactions for medicines. CYP2C9 is one of the major isoforms of CYP family, which metabolizes S-warfarin to 7-hydroxywarfarin and 6-hydroxywarfarin (Kaminsky and Zhang 1997). The human CYP2C9 gene is approximately $55 \mathrm{~kb}$ long and located on chromosome 10q24.2 (Meehan et al. 1988; Goldstein and de Morais 1994). Among the genetic variants reported in the human CYP2C9 gene (Sim and Ingelman-Sundberg 2013), CYP2C9 *2 (rs1799853, c.430C > T, p.Arg144Cys) and CYP2C9 *3 (rs1057910, c.1075A > C, p.Ile359Leu) alleles are relatively frequent minor alleles in Caucasians, influencing warfarin metabolism (Higashi et al. 2002). CYP2C $\% 1$ allele distributes widely in any ethnic groups, denoted as the wild type (Yin and Miyata 2007). For Swarfarin to 7-hydroxylation, CYP2C9 enzyme activity with *2 allele showed $50 \%$ reduction in $\mathrm{V}_{\max }$ (maximum velocity) and a higher $K_{m}$ (Michaelis constant) compared with the wild type (Rettie et al. 1994; Sullivan-Klose et al. 1996; Yamazaki et al. 1998; Yin and Miyata 2007). CYP2C9 *3 showed a more marked reduction of approximately $90 \%$ of the proper clearance $\left(\mathrm{V}_{\max } / \mathrm{K}_{\mathrm{m}}\right)$ compared with the wild type (Rettie et al. 1994; Sullivan-Klose et al. 1996; Yamazaki et al. 1998; Yin and Miyata 2007). These reports show that $C Y P 2 C 9 * 2$ and *3 variants are highly implicated in warfarin metabolism (Aithal et al. 1999). According to the HapMap data, Asians and Africans have no *2 of CYP $2 C 9$.

In line with these findings, genotyping both $V K O R C 1$ G-1639A and CYP2C9*3 is considered to be useful to find an appropriate individual warfarin dosage for Asians and Africans. In August 2007, the Food and Drug Administration (FDA) in the United States actually approved revisions of attached document for warfarin, following the reports of effects of VKORC1 and CYP2C9 on dose requirements (Vladutiu 2008). The FDA recommend that patients possessing these variants be considered to start from a lower initial dose to avoid the risk of bleeding.

For genotyping, several methods have been reported including polymerase chain reaction-restriction fragments length polymorphism (PCR-RFLP) (Erlich et al. 1991), real-time PCR using TaqMan probes (De la Vega et al. 2005), DNA microarray method (Nishida et al. 2007) and quenching probe method (Tani et al. 2009). Each method has limitations, and time and costs for genotyping vary among the methods. We have developed a quick and inexpensive genotyping method named PCR with confronting two-pair primers (PCR-CTPP) (Hamajima et al. 2000; Hamajima 2001), and applied it for many SNPs. This paper describes the feasibility to genotype VKORC1 G-1639A and CYP2C9 *3 with the PCRCTPP for clinical warfarin use.

\section{Subjects and methods Subjects}

Study subjects were 436 examinees (117 males and 319 females, aged 32 to 85 years) who attended a health checkup program supported by the Nagoya municipal government in 2000. The examinees were inhabitants of Nishi ward at Nagoya city in Japan. A written informed consent to anonymous uses of the residual blood for genetic tests as well as information on demographic characteristics was obtained when the health checkup. About $2 \mathrm{ml}$ of blood was left after a routine test for health check.

Among 489 examinees invited to the study, 468 (95.7\%) agreed to provide their residual blood for genetic tests and related information. Three residual blood samples were not available for DNA extraction. In addition, 29 extracted buffy coat samples were used up for other genotyping in previous studies (Hamajima et al. 2001; 2002; 2003). The remaining 436 examinees were subjects in this study.

For both VKORC1 G-1639A and CYP2C9 A1075C, 436 examinees were tested by DigiTag2 method to confirm results of genotyping by PCR-CTPP. For CYP2C9 A1075C, each of two subjects with $* 1 * 1, * 1 * 3$, and $* 3 * 3$ among 5,017 participants (3,413 males and 1,604 females, aged 35 to 69 years) in Shizuoka area of the Japan Multi-Institutional Collaborative Cohort Study (J-MICC Study) (Asai et al. 2009) were genotyped by PCR-CTPP in order to confirm whether the genotype information are accorded with those obtained by DigiTag2 method.

\section{Genotyping}

DNA for 436 health check examinees in this study was extracted from the buffy coat fraction preserved at $-40^{\circ} \mathrm{C}$ by a QIAamp DNA Blood Mini Kit (QIAGEN Inc., Valencia, CA). The SNPs were genotyped by PCR-CTPP, and the basic logic has been reported previously (Hamajima et al. 2000; Hamajima 2001). This method requires four primers (two pairs) for each allele specific amplification; F1 and $\mathrm{R} 1$ for $X$ allele, and F2 and R2 for the $Y$ allele (shown in Figure 1). The end base of R1 and F2 should be the position of SNP. The PCR amplifies three different-sized bands of DNA; between F1 and R1, between F2 and R2, and between $\mathrm{F} 1$ and $\mathrm{R} 2$. The primer sequences for VKORC1 G-1639A and CYP2C9 A1075C were shown with the melting temperatures estimated by base sequence algorithm (Breslauer et al. 1986) in Table 1.

The PCR was performed with initial denaturation at $95^{\circ} \mathrm{C}$ for $10 \mathrm{~min}$, followed by 30 cycles of denaturation at $95^{\circ} \mathrm{C}$ for $1 \mathrm{~min}$, annealing at $62^{\circ} \mathrm{C}$ for $\mathrm{CYP} 2 \mathrm{C} 9 \mathrm{~A} 1075 \mathrm{C}$ and at $61^{\circ} \mathrm{C}$ for $V K O R C 1 \mathrm{G}-1639 \mathrm{~A}$ for $1 \mathrm{~min}$, and extension at $72^{\circ} \mathrm{C}$ for $1 \mathrm{~min}$. The final extension was at $72^{\circ} \mathrm{C}$ for $5 \mathrm{~min}$.

On the other hand, DNA for participants in Shizuoka area of the J-MICC Study was extracted from the buffy coat fraction by BioRobot ${ }^{\ominus}$ M48 (QIAGEN group, Tokyo, 


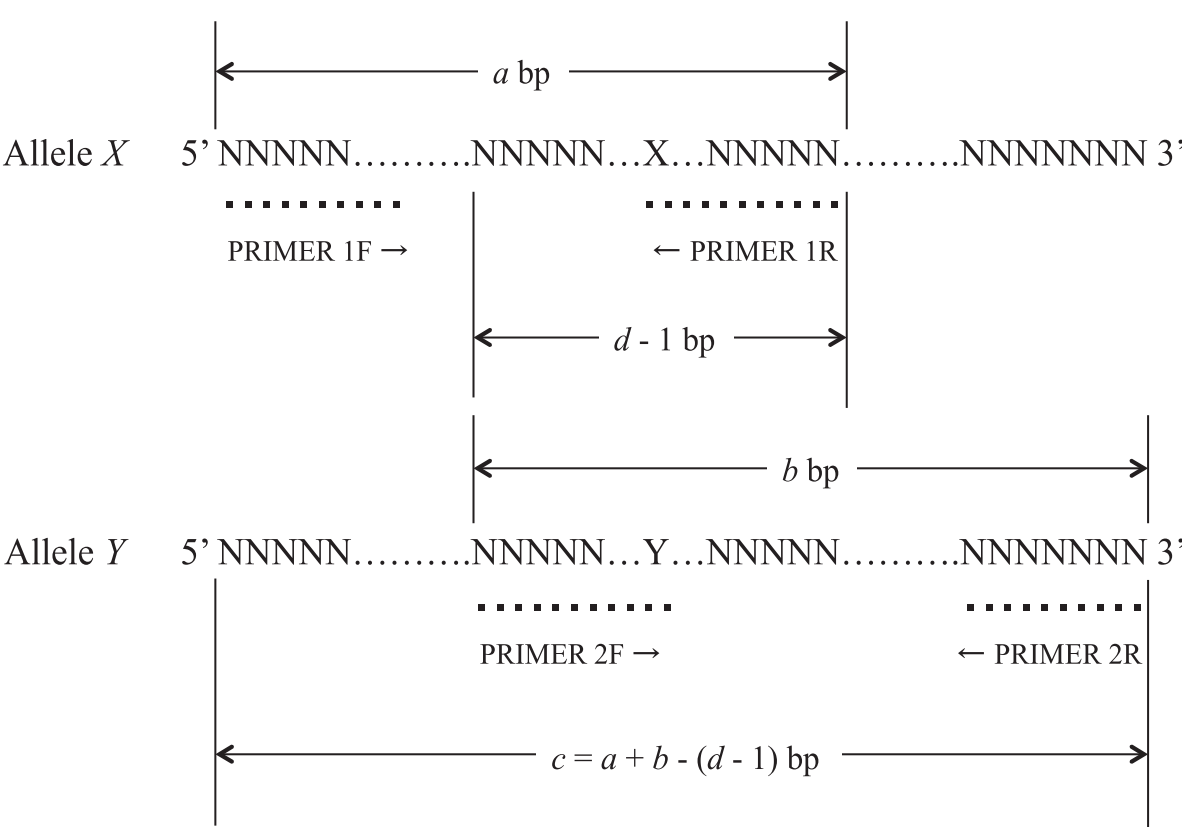

Figure 1 Logic of PCR-CTPP. a, size for $X$ allele; $\mathbf{b}$, size for $Y$ allele; $\mathbf{c}=a+b-(d-1)$, size between primers $1 \mathrm{~F}$ and $2 R$; $\mathbf{d}$, Sum of the size of primers $2 \mathrm{~F}$ and $1 \mathrm{R}$. PCR-CTPP = Polymerase chain reaction with confronting two-pair primers.

Japan). They were genotyped by DigiTag2 method (NGK INSULATORS, Ltd., Nagoya, Japan) (Nishida et al. 2007).

\section{Results}

Figure 2 shows actual gels for VKORC1 G-1639A (rs9923231) in Gel (A) and CYP2C9 A1075C (rs1570910) in Gel (B) obtained by PCR-CTPP. Each Sample (from one to six in Figure 2) was different one. Among 436 subjects, there was no one with $* 3 * 3$ of CYP2C9 because of the less frequency. We therefore selected the subjects with $* 3 * 3$ among participants of Shizuoka area in the J-MICC Study in order to genotyping by PCR-CTPP.
The genotype information $(* 1 * 1, * 1 * 3$, and $* 3 * 3$ : each of two samples) of Shizuoka area obtained by DigiTag2 method was accorded with that obtained by PCR-CTPP. There was no genotype information for VKORC1 G-1639A in Shizuoka area of the J-MICC Study. Both VKORC1 G-1639A and CYP2C9 A1075C for 436 examinees were replicated by DigiTag2 method.

Table 2 shows the genotype frequencies of VKORC1 G-1639A and CYP2C9 A1075C. Each allele frequency was all in Hardy-Weinberg equilibrium. As failed genotyping, there were $10(2.3 \%, \mathrm{n}=436)$ for VKORC1 G$1639 \mathrm{~A}$, and four $(0.9 \%, \mathrm{n}=436)$ for CYP2C9 A1075C. Comparisons between these allele frequencies and those

Table 1 Primer sequences of PCR-CTPP for VKORC1 G-1639A and CYP2C9 A1075C

\begin{tabular}{lll}
\hline Primers & Sequences & \\
\hline VKORC1 G-1639A F1 & 5' CAC AGA CGC CAG AGG AAG AGA G & T' $)$ \\
VKORC1 G-1639A R1 & 5' CGT GAG CCA CCG CAC CT & 64.0 \\
VKORC1 G-1639A F2 & 5' GAA GAC CTG AAA AAC AAC CAT TGG CCG \\
VKORC1 G-1639A R2 & 5' CTC AGC CTC CCA AGT AGT TTG G \\
CYP2C9 A1075C F1 & 5' CCA GGA AGA GAT TGA ACG TGT GAT TG \\
CYP2C9 A1075C R1 & 5' TGG TGG GGA GAA GGT CAA T \\
CYP2C9 A1075C F2 & 5' GCA CGA GGT CCA GAG ATA CC \\
CYP2C9 A1075C R2 & 5' GAG TTA TGC ACT TCT CTC ACC CG & 62.1 \\
\hline
\end{tabular}

CYP = Cytochrome P450, PCR-CTPP = Polymerase chain reaction with confronting two-pair primers, Tm = Melting temperature, $V K O R C 1=$ Vitamin $K$ epoxide reductase complex, subunit 1.

Polymorphic bases are indicated in bold type. 

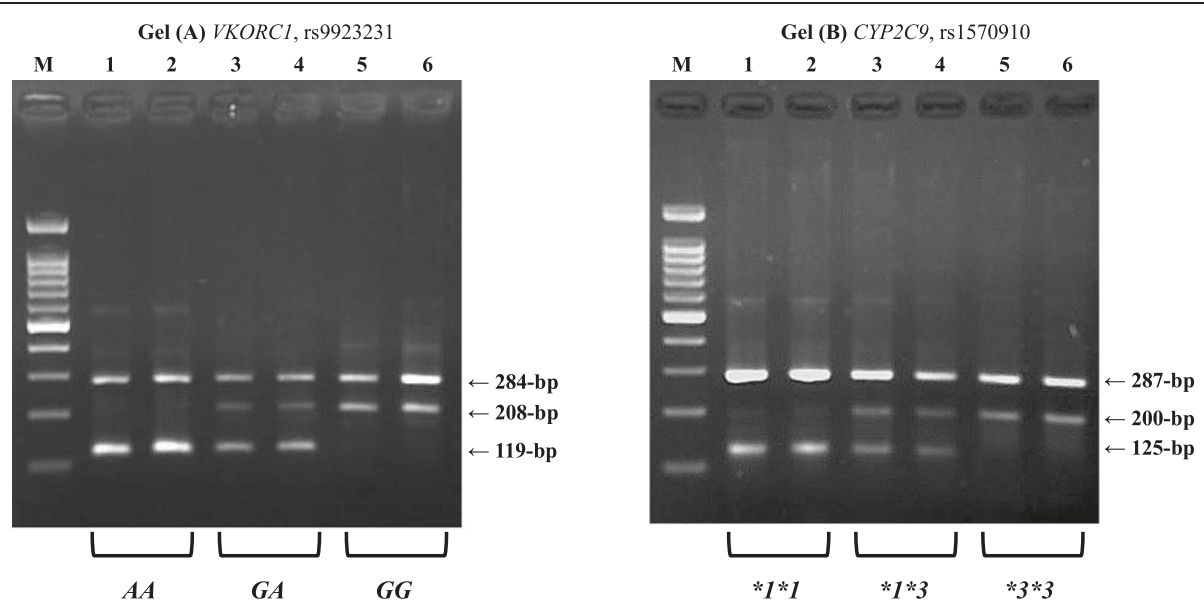

Figure 2 Representative gels. (A) VKORC1 rs9923231 polymorphism. Lane M, a 100-bp ladder; lanes 1 and 2, an AA homozygote with fragments of 119-bp and 284-bp; lanes 3 and 4, a GA heterozygote with fragments of 119-bp, 208-bp and 284-bp; and lanes 5 and 6, a GG with fragments of 208-bp and 284-bp. (B) CYP2C9 rs1570910 polymorphism. Lane M, a 100-bp ladder; lanes 1 and 2, a *1*1 homozygote with fragments of 125-bp and 287-bp; lanes 3 and 4, a * $1 * 3$ heterozygote with fragments of 125-bp, 200-bp and 287-bp; and lanes 5 and 6, a *3*3 with fragments of 200-bp and 287-bp. CYP = Cytochrome P450, VKORC1 = Vitamin K epoxide reductase complex, subunit 1.

reported in the other study and the HapMap project were shown in Table 3, which were all fairly similar.

\section{Discussion}

In this study, we finely conducted the genotyping for VKORC1 G-1639A and CYP2C9 A1075C using PCRCTPP method. The allele frequencies were confirmed to be reasonable by the comparisons with those reported in the HapMap data. Both SNPs for 436 examinees

Table 2 Genotypes and allele frequencies for VKORC1 G-1639A and CYP2C9 A1075C obtained by PCR-CTPP

\begin{tabular}{lcccc}
\hline Gene & N & $\begin{array}{c}\text { Frequency } \\
(\%)\end{array}$ & $\begin{array}{c}\text { Allele } \\
\text { frequency }\end{array}$ & $\begin{array}{c}\text { Hardy-Weinberg } \\
\text { equilibrium } p\end{array}$ \\
\hline
\end{tabular}

VKORC1 (rs9923231,

c. $-1639 \mathrm{G}>\mathrm{A})$

Nagoya

$\begin{array}{rcccc}G G & 2 & 0.5 & G & 0.085 \\ G A & 68 & 16.0 & A & 0.915 \\ A A & 356 & 83.5 & & \\ \text { Total } & { }^{\mathrm{a}} 426 & 100 & & \end{array}$

CYP2C9 (rs1057910

C. $1075 \mathrm{~A}>$ C)

Nagoya

$$
\begin{array}{rcccc}
A A\left({ }^{*} *^{*} 1\right) & 414 & 95.8 & { }^{*} 1 & 0.979 \\
A C\left({ }^{*} *^{*} 3\right) & 18 & 4.2 & *^{*} & 0.021 \\
C C\left(*^{*} 3\right) & 0 & 0 & & \\
\text { Total } & { }^{b} 432 & 100 & &
\end{array}
$$

$C Y P=$ Cytochrome P450, PCR-CTPP = Polymerase chain reaction with confronting two-pair primers, VKORC1 = Vitamin $K$ epoxide reductase complex, subunit 1 . ${ }^{a}$ Data was missing for 10 subjects with unsuccessful genotyping.

${ }^{\mathrm{b}}$ Four were failed. were replicated by DigiTag2 method. These results have proved that PCR-CTPP is applicable for genotyping VKORC1 G-1639A and CYP2C9 A1075C.

For genotyping SNPs, several studies have recommended their options (Erlich et al. 1991; De la Vega et al. 2005; Nishida et al. 2007; Tani et al. 2009). Among them, PCRRFLP and TaqMan method are commonly used. Nonetheless, they were not necessarily confirmed to have the feasibility or be reasonable for genotyping VKORC1 G-1639A and CYP2C9 $* 3$ for tailored warfarin use. Besides, former needs a longer time and later is quick with expensiveness for genotyping.

The main difference between PCR-CTPP and PCRRFLP is that PCR-CTPP dose not need incubation with restriction enzymes for PCR product digestion. PCR-

\begin{tabular}{|c|c|c|c|c|}
\hline \multirow[t]{2}{*}{ Allele frequency } & \multicolumn{2}{|c|}{$\begin{array}{c}\text { VKORC1 c.-1639G > A } \\
\text { (rs9923231) }\end{array}$} & \multicolumn{2}{|c|}{$\begin{array}{c}\text { CYP2C9 c.1075A }>C \\
\text { (rs1057910) }\end{array}$} \\
\hline & $G$ & $A$ & $A$ & $C$ \\
\hline Nagoya citizen & 0.085 & 0.915 & 0.979 & 0.021 \\
\hline \multicolumn{5}{|l|}{ HapMap projects } \\
\hline African & 0.978 & 0.022 & 1.000 & 0.000 \\
\hline Caucasian & 0.602 & 0.398 & 0.942 & 0.058 \\
\hline Chinese & 0.058 & 0.942 & 0.953 & 0.047 \\
\hline Japanese & 0.099 & 0.901 & 0.977 & 0.023 \\
\hline \multicolumn{5}{|l|}{$\begin{array}{l}\text { Japanese in } \\
\text { Shizuoka area }\end{array}$} \\
\hline Yoshizawa, et al. 2009 & 0.082 & 0.918 & 0.979 & 0.021 \\
\hline
\end{tabular}
CTPP therefore has an advantage of lowest cost only for

Table 3 Comparisons of allele frequencies for VKORC1 G-1639A and CYP2C9 A1075C 
primers and polymerase. There is no restriction enzyme step in PCR-CTPP, which means that we could conduct the genotyping only half of the time compared with PCR-RFLP. Recently, use of real-time PCR was also developed for genotyping SNPs (De la Vega et al. 2005), although the cost per one sample is still too expensive (about two dollars), and the method needs exclusive machines in laboratory as in DigTag2 and Q-probe methods (Nishida et al. 2007; Tani et al. 2009). In contrast, the cost of PCR-CTPP is only half dollar per one sample (as costs of primers and Taq polymerase).

Some technical problems have been reported for PCRCTPP (Hamajima et al. 2002). The strength of bands is dependent on the balance in melting temperature of each primer. Addition of one base to a primer changes its melting temperature and causes distraction of the balance of the bands strength. The melting temperatures varied in a wide range (shown in Table 1). The optimum primers and all the condition in this study were determined after several unsuccessful combinations. However, a further option that one primer amplification of PCRCTPP products (OPA-CTPP) has been developed for resolving these problems (Yin et al. 2012).

As limitations, we could not verify the detection for *2 of CYP2C9 because almost all Japanese have no *2 of CYP2C9 as well as other Asians and Africans. It needs to confirm those with the $* 2$ using PCR-CTPP for Caucasian. Additionally, it may also need to confirm those with *5, *6, *8, and $" 11$ in relation to warfarin dose for Africans, when the frequencies are considered to be high on the clinical practice (Limdi et al. 2008; Scott et al. 2009).

The proportions of failed genotyping seem to be relatively high. These phenomena, however, would be explained by buffy condition (i.e., lowered concentration, insufficient amount of sample, or DNA degradation over time).

Using PCR-CTPP, we have already succeeded in other tailored therapy and prevention. The details were described elsewhere (Tamura et al. 2011, 2012). Tailored warfarin therapy in clinical practice could also be supported by PCR-CTPP, especially among Japanese.

\section{Conclusion}

We suggested that PCR-CTPP would be useful when genotyping VKORC1 G-1639A and CYP2C9*3 is needed in tailored warfarin use for Asians and Africans. Application, experience, and further data in real patients with warfarin therapy would be warranted hereafter. Establishment in other tailored therapy is also expected.

\footnotetext{
Abbreviations

CYP: Cytochrome P450; FDA: Food and drug administration; J-MICC Study: Japan Multi-Institutional Collaborative Cohort Study; OPA-CTPP: One primer amplification of polymerase chain reaction with confronting two-pair
}

primers products; PCR-CTPP: Polymerase chain reaction with confronting two-pair primers; PCR-RFLP: Polymerase chain reaction-restriction fragments length polymorphism; PT-INR: Prothrombin time measured with an international normalized ratio; SNP: Single nucleotide polymorphism; VKORC1: Vitamin K epoxide reductase complex, subunit 1.

\section{Competing interests}

The authors declare that they have no competing interests.

\section{Authors' contributions}

$\Pi$ carried out the design for primer sequences and genotyped SNPs, and drafted the manuscript. NK participated in acquisition and interpretation of data. $\mathrm{NH}$ conceived of the study, and participated in its design and coordination and helped to draft the manuscript. All authors read and approved the final manuscript.

\section{Acknowledgments}

The authors are grateful to Ms. Yoko Mitsuda and Ms. Keiko Shibata for her technical assistance. This work was supported in part by Grants-in-Aid for Scientific Research on Priority Areas of Cancer from the Ministry of Education, Culture, Sports, Science and Technology of Japan.

\section{Author details}

'Department of Epidemiology and Preventive Medicine, Gifu University Graduate School of Medicine, 1-1 Yanagido, Gifu 501-1194, Japan. ${ }^{2}$ Nagoya City Meito Health Center, Nagoya, Japan. ${ }^{3}$ Department of Healthcare Administration, Nagoya University Graduate School of Medicine, Nagoya, Japan.

Received: 16 June 2014 Accepted: 27 August 2014

Published: 5 September 2014

\section{References}

Aithal GP, Day CP, Kesteven PJ, Daly AK (1999) Association of polymorphisms in the cytochrome P450 CYP2C9 with warfarin dose requirement and risk of bleeding complications. Lancet 353:717-719

Asai Y, Naito M, Suzuki M, Tomoda A, Kuwabara M, Fukada Y, Okamoto A, Oishi S, Ikeda K, Nakamura T, Misu Y, Katase S, Tokumasu S, Nishio K, Ishida Y, Hishida A, Morita E, Kawai S, Okada R, Wakai K, Tamakoshi A, Hamajima N (2009) Baseline data of Shizuoka area in the Japan Multi-Institutional Collaborative Cohort Study (J-MICC Study). Nagoya J Med Sci 71:137-144

Breslauer KJ, Frank R, Blöcker H, Marky LA (1986) Predicting DNA duplex stability from the base sequence. Proc Natl AcadSci USA 86:3746-3750

D'Andrea G, D'Ambrosio RL, Di Perna P, Chetta M, Santacroce R, Brancaccio V, Grandone E, Margaglione M (2005) A polymorphism in the VKORC1 gene is associated with an inter-individual variability in the dose-anticoagulant effect of warfarin. Blood 105:645-649

De la Vega FM, Lazaruk KD, Rhodes MD, Wenz MH (2005) Assessment of two flexible and compatible SNP genotyping platforms: TaqMan SNP genotyping assays and the SNPlex genotyping system. Mutat Res 573:111-135

Erlich HA, Gelfand D, Sninsky JJ (1991) Recent advances in the polymerase chain reaction. Science 252:1643-1651

Goldstein JA, de Morais SM (1994) Biochemistry and molecular biology of the human CYP2C subfamily. Pharmacogenetics 4:285-299

Hamajima N (2001) PCR-CTPP: A new genotyping technique in the era of genetic epidemiology. Expert Rev Mol Diagn 1:119-123

Hamajima N, Saito T, Matsuo K, Kozaki K, Takahashi T, Tajima K (2000) Polymerase chain reaction with confronting two-pair primers for polymorphism genotyping. Jpn J Cancer Res 91:865-868

Hamajima N, Katsuda N, Matsuo K, Saito T, Ito LS, Ando M, Inoue M, Takezaki T, Tajima K (2001) Smoking habit and interleukin IB C-31T polymorphism. J Epidemiol 11:120-125

Hamajima N, Saito T, Matsuo K, Tajima K (2002a) Competitive amplification and unspecific amplification in polymerase chain reaction with confronting two-pair primers. J Mol Diagn 4:103-107

Hamajima N, Shibata A, Ikehara Y, Katsuda N, Mori S, Ito H, Matsuo K, Tajima K, Tominaga S (2002b) Lack of consistency in the associations of Helicobacter pylori seropositivity with Se and Le polymorphisms among Japanese. Gastric Cancer 5:194-200

Hamajima N, Katsuda N, Matsuo K, Saito T, Hirose K, Inoue M, Zaki T, Tajima K, Tominaga S (2003) High anti-Helicobacter pylori antibody seropositivity 
associated with the combination of IL-8-251TT and IL-10-819TT genotypes Helicobacter 8:105-110

Higashi MK, Veenstra DL, Kondo LM, Wittkowsky AK, Srinouanprachanh SL, Farin FM, Rettie AE (2002) Association between CYP2C9 genetic variants and anticoagulation-related outcomes during warfarin therapy. JAMA 287:1690-1698

Kaminsky LS, Zhang ZY (1997) Human P450 metabolism of warfarin. Pharmacol Ther 73:67-74

Li T, Chang CY, Jin DY, Lin PJ, Khvorova A, Stafford DW (2004) Identification of the gene for vitamin $\mathrm{K}$ epoxide reductase. Nature 427:541-544

Limdi NA, McGwin G, Goldstein JA, Beasley TM, Arnett DK, Adler BK, Baird MF, Acton RT (2008) Influence of CYP2C9 and VKORC1 1173C/T genotype on the risk of hemorrhagic complications in African-American and EuropeanAmerican patients on warfarin. Clin Pharmacol Ther 83:312-321

Meehan RR, Gosden JR, Rout D, Hastie ND, Friedberg T, Adesnik M, Buckland R, van Heyningen V, Fletcher J, Spurr NK, Sweeney J, Wolf CR (1988) Human cytochrome P-450 PB-1: a multigene family involved in mephenytoin and steroid oxidations that maps to chromosome 10. Am J Hum Genet 42:26-37

Nelsestuen GL, Zytkovicz TH, Howard JB (1974) The mode of action of vitamin K. Identification of gamma-carboxyglutamic acid as a component of prothrombin. J Biol Chem 249:6347-6350

Nishida N, Tanabe T, Takasu M, Suyama A, Tokunaga K (2007) Further development of multiplex single nucleotide polymorphism typing method, the DigiTag2 assay. Anal Biochem 364:78-85

Rettie AE, Wienkers LC, Gonzalez FJ, Trager WF, Korzekwa KR (1994) Impaired (S)- warfarin metabolism catalysed by the R144C allelic variant of CYP2C9. Pharmacogenetics 4:39-42

Rieder MJ, Reiner AP, Gage BF, Nickerson DA, Eby CS, McLeod HL, Blough DK, Thummel KE, Veenstra DL, Rettie AE (2005) Effect of VKORC1 haplotypes on transcriptional regulation and warfarin dose. N Engl J Med 352:2285-2293

Rost S, Fregin A, Ivaskevicius V, Conzelmann E, Hörtnagel K, Pelz HJ, Lappegard K, Seifried E, Scharrer I, Tuddenham EG, Müller CR, Strom TM, Oldenburg J (2004) Mutations in VKORC1 cause warfarin resistance and multiple coagulation factor deficiency type 2. Nature 427:537-541

Scott SA, Jaremko M, Lubitz SA, Kornreich R, Halperin JL, Desnick RJ (2009) CYP2C9*8 is prevalent among African-Americans: implications for pharmacogenetic dosing. Pharmacogenomics 10:1243-1255

Sim SC, Ingelman-Sundberg M (2013) Update on allele nomenclature for human cytochromes P450 and the Human Cytochrome P450 Allele (CYP-allele) Nomenclature Database. Methods Mol Biol 987:251-259

Stenflo J, Fernlund P, Egan W, Roepstorff P (1974) Vitamin K dependent modifications of glutamic acid residues in prothrombin. Proc Natl Acad Sci U S A 71:2730-2733

Sullivan-Klose TH, Ghanayem BI, Bell DA, Zhang ZY, Kaminsky LS, Shenfield GM, Miners JO, Birkett DJ, Goldstein JA (1996) The role of the CYP2C9-Leu359 allelic variant in the tolbutamide polymorphism. Pharmacogenetics 6:341-349

Suttie JW (1987) The biochemical basis of warfarin therapy. Adv Exp Med Biol 214:3-16

Tamura T, Kurata M, Inoue S, Kondo T, Goto Y, Kamiya Y, Kawai S, Hamajima N (2011) Improvements in Helicobacter pylori eradication rates through clinical CYP2C19 genotyping. Nagoya J Med Sci 73:25-31

Tamura T, Kurata M, Kondo T, Goto Y, Kamiya Y, Kawai S, Mitsuda Y, Hamajima N (2012) Preventive medical services not covered by public health insurance at Daiko Medical Center in Japan, 2004-2011. Nagoya J Med Sci 74:115-121

Tani H, Miyata R, Ichikawa K, Morishita S, Kurata S, Nakamura K, Tsuneda S, Sekiguchi Y, Noda N (2009) Universal quenching probe system: flexible, specific, and cost-effective real-time polymerase chain reaction method. Anal Chem 81:5678-5685

Vladutiu GD (2008) The FDA announces new drug labeling for pharmacogenetic testing: is personalized medicine becoming a reality? Mol Genet Metab 93:1-4

Yamazaki H, Inoue K, Chiba K, Ozawa N, Kawai T, Suzuki Y, Goldstein JA, Guengerich FP, Shimada T (1998) Comparative studies on the catalytic roles of cytochrome P450 2C9 and its Cys- and Leu-variants in the oxidation of warfarin, flurbiprofen, and diclofenac by human liver microsomes. Biochem Pharmacol 56:243-251

Yin T, Miyata T (2007) Warfarin dose and the pharmacogenomics of CYP2C9 and VKORC1 - rationale and perspectives. Thromb Res 120:1-10

Yin G, Mitsuda Y, Ezaki T, Hamajima N (2012) A new PCR method: one primer amplification of PCR-CTPP products. Mol Biotechnol 52:180-183

Yoshizawa M, Hayashi H, Tashiro Y, Sakawa S, Moriwaki H, Akimoto T, Doi O, Kimura M, Kawarasaki Y, Inoue K, Itoh K (2009) Effect of VKORC1-1639 G>A polymorphism, body weight, age, and serum albumin alterations on warfarin response in Japanese patients. Thromb Res 124:161-166

Yuan HY, Chen JJ, Lee MT, Wung JC, Chen YF, Charng MJ, Lu MJ, Hung CR, Wei $\mathrm{CY}$, Chen CH, Wu JY, Chen YT (2005) A novel functional VKORC1 promoter polymorphism is associated with inter-individual and inter- ethnic differences in warfarin sensitivity. Hum Mol Genet 14:1745-1751

Zimmermann A, Matschiner JT (1974) Biochemical basis of hereditary resistance to warfarin in the rat. Biochem Pharmacol 23:1033-1040

doi:10.1186/2193-1801-3-499

Cite this article as: Tamura et al: A PCR method for VKORC1 G-1639A and CYP2C9 A1075C genotyping useful to warfarin therapy among Japanese. SpringerPlus 2014 3:499.

\section{Submit your manuscript to a SpringerOpen ${ }^{\circ}$ journal and benefit from:}

- Convenient online submission

- Rigorous peer review

- Immediate publication on acceptance

- Open access: articles freely available online

- High visibility within the field

- Retaining the copyright to your article

Submit your next manuscript at $\gg$ springeropen.com 